\title{
Jeugdige dader, volwassen straf?
}

\author{
I. Weijers*
}

\section{Inleiding}

De afgelopen jaren zijn we meerdere malen geconfronteerd met afschuwelijke geweldsmisdrijven waarbij jonge daders waren betrokken, soms met dodelijke afloop. Dat was bijvoorbeeld het geval bij de aanslag op Hans van Wieren, conrector van het Terra College in Den Haag, bij de moord op Maja Bradaric in Bemmel en bij het doodschoppen van Anja Joos in Amsterdam. Naar aanleiding van dergelijke zaken rijst altijd meteen de vraag of de betrokken jongeren wel volgens het relatief milde jeugdstrafrecht moeten worden berecht. Opvallend aan deze drie zaken was in elk geval dat de betrokken minderjarigen allen werden berecht volgens het commune strafrecht. De hoofdregel in het Nederlandse strafrecht luidt dat elke jongere in de leeftijd van twaalf tot achttien jaar wordt berecht volgens het jeugdstrafrecht. Artikel 77 b Sr biedt de rechter echter de mogelijkheid verdachten die ten tijde van het delict 16 of 17 jaar oud waren te berechten volgens het gewone strafrecht, indien hij hiertoe aanleiding vindt in de ernst van het misdrijf, de persoonlijkheid van de dader of de omstandigheden waaronder het misdrijf is begaan. Het is duidelijk dat dit onderwerp, zeker waar het het tweede criterium betreft - de persoonlijkheid van de dader direct raakt aan de forensische psychiatrie en psychologie.

Om iets over dit onderwerp te berde te kunnen brengen wil ik allereerst kijken naar de grondslag van het jeugdstrafrecht: waarom hebben we een apart jeugdstrafrecht? Vervolgens zal ik een en ander naar voren brengen over de wijze waarop de grens tussen jeugdstrafrecht en gewoon strafrecht in de praktijk wordt gehanteerd. Ik zal tien zaken waarbij het commune

* Ido Weijers is pedagoog, verbonden aan de Faculteit Sociale Wetenschappen van de Universiteit Utrecht en bijzonder hoogleraar Jeugdrechtspleging aan het Willem Pompe Instituut voor Strafrechtwetenschappen van dezelfde universiteit. 
strafrecht bij minderjarige verdachten is toegepast analyseren. Tenslotte zal ik een aantal uiteenlopende argumenten tegen deze toepassing naar voren brengen, maar ook één argument voor.

\section{Adolescentie}

De grondslag van een apart jeugdstrafrecht wordt gevonden in de specifieke status van de adolescent. In het onderzoek naar de kinderlijke ontwikkeling is de afgelopen decennia alleen maar meer steun gekomen voor de aloude intuïtie dat we bij jongeren die over de schreef gaan niet eenvoudig op dezelfde manier kunnen reageren als bij volwassenen. Dat onderzoek berust op twee peilers. Enerzijds is dat de ontwikkelingspsychologie, vanwaaruit de afgelopen decennia meer bekend is geworden over de kinderlijke ontwikkeling, waarbij wordt gesproken van ontwikkelingstaken en ontwikkelingspaden. ${ }^{1}$ Anderzijds heeft het hersenonderzoek de laatste vijf à tien jaar aangetoond dat rond de leeftijd van zestien of zeventien jaar nog een aanzienlijke groeispurt plaatsvindt. De hersenen van adolescenten en de integratie van informatie uit verschillende hersengebieden blijken nog niet volledig ontwikkeld te zijn. ${ }^{2}$

De adolescentie wordt om een aantal redenen als een duidelijke overgangsfase in de menselijke ontwikkeling gezien. Het uitgangspunt van elke studie wordt gevormd door de constatering van de snelle en dramatische veranderingen die in deze fase plaatsvinden. Dan gaat het allereerst om veranderingen in lichamelijk en seksueel opzicht en om de psychische verwerking van deze groeiprocessen en de sociale reactie daarop. Typerend is daarbij dat zich tegelijkertijd snelle veranderingen voordoen in intellectuele, emotionele en sociale vaardigheden en vermogens. Een tweede kenmerk van deze fase is de extreme variëteit in en tussen individuen. Fysieke rijpheid kan op een verwarrende wijze samengaan met emotionele onvolwassenheid; sociale vaardigheden kunnen samengaan met (en het zicht ontnemen op) intellectuele achterstand, etc. Ten derde kenmerkt deze periode zich door een uitzonderlijk sterke beïnvloedbaarheid, met name voor ervaringen in de directe sociale omgeving.

1 Zie bijvoorbeeld Koops \& Slot 1998

2 Doreleijers \& Jansen, 2004 
Meer specifiek met het oog op het jeugdstraf(proces)recht zijn twee aspecten van belang: het oordeelsvermogen en het vermogen tot volwaardige participatie in het strafproces. Wat het eerste betreft kan ondanks alle individuele verschillen met betrekking tot de materiële kant en de beantwoording van de schuldvraag worden vastgesteld dat het zelfstandig oordeelsvermogen normaal gesproken pas rond het zestiende jaar in principe vergelijkbaar is met dat van volwassenen. ${ }^{3}$ Toch moet er meteen op een aanzienlijke beperking worden gewezen. Dit is namelijk een typisch 'laboratoriumgegeven'. Het cognitieve vermogen om in alle rust in een overzichtelijke 'pen-en-papier'-test tot een afgewogen oordeel te komen is nog iets heel anders dan daar in de veel minder overzichtelijke alledaagse werkelijkheid naar te handelen. Voor de groep jongeren over wie wij het hier hebben - minderjarigen die een zeer ernstig, en in die zin 'volwassen misdrijf' plegen - zijn tenminste vier veelal samenhangende factoren van belang die dit startpunt in feite aanzienlijk verder leggen: gebrek aan ervaring, impulsiviteit, groepsdruk en ongunstige omgeving. ${ }^{4}$

Allereerst speelt bij de doorsnee-adolescent het gebrek aan ervaring dat de meeste jongeren met allerlei kwesties nu eenmaal hebben, ook nog als ze zestien of zeventien zijn, hen gemakkelijk parten. Voor veel jongeren geldt dat ze in principe rond hun zestiende allerlei puzzels en praktische zowel als ethische problemen kunnen doorzien en over talloze zaken intelligente opmerkingen kunnen maken, maar ze hebben nog geen of nauwelijks praktische ervaring met dergelijke puzzels in de praktijk opgedaan. Een zeer belangrijke rol speelt hierbij hun geringe vermogen om impulsen te bedwingen. Dat is een van de eerste dingen die bijvoorbeeld opvalt bij hun drink- en rijgedrag. In een laboratoriumsituatie mogen jongeren vaak prima in staat zijn tot de juiste beslissing; in een praktische situatie valt het, zeker de jongens, vaak bijzonder moeilijk weerstand te bieden aan hun impulsen. Impulsen, die gepaard gaan met onderschatting van risico's en overschatting van eigen kunnen, die op hun beurt weer samenhangen met gebrek aan ervaring.

Dit ontwikkelingspsychologisch inzicht krijgt de laatste jaren sterke ondersteuning vanuit het moderne hersenonderzoek. De hersenen van adolescenten blijken namelijk nog niet volledig ontwikkeld en sommige

3 Steinberg \& Cauffman 1996.

4 Scott, Repucci \& Woolard 1995. 
structuren worden ook op een andere manier gebruikt. Er is nog geen volledige integratie van informatie uit verschillende hersengebieden. Gebieden die te maken hebben met het verwerken van emoties bij adolescenten worden nog niet zo duidelijk gecontroleerd door de prefontale cortex. Er zit met andere woorden nog geen duidelijke rem op emotioneel gedrag. Kortom, dat gedeelte van de hersenactiviteit dat relevant is in strafrechtelijk opzicht, rijpt pas vrij laat. Al kunnen adolescenten dus in rustige en geïsoleerde 'laboratoriumsituaties' redeneren als volwassenen, in hun praktisch handelen beschikken ze pas (ruim) na hun zeventiende over alle mogelijkheden om hun gedrag geheel zelfstandig te sturen.

Dit punt speelt uiteraard een belangrijke rol als het gaat om de vaststelling van de mate van verantwoordelijkheid en schuld. Daarbij komen twee andere factoren, die bij uitstek van belang zijn bij de jongeren over wie wij het hier hebben. Ten eerste zijn adolescenten zoals gezegd in het algemeen ook veel sterker beïnvloedbaar dan kinderen en dan volwassenen. Ze zijn met name bijzonder gevoelig voor groepsdruk, de groep van vrienden, leeftijdgenoten, jongeren bij wie ze het gevoel hebben te horen. Voor jongeren die ernstig over de schreef gaan spelen deze factoren in de meeste gevallen een bijzonder grote rol, zeker als die vrienden zelf meer of minder regelmatig delicten plegen, of die schijn weten te wekken, wapens dragen, over ernstige delicten praten alsof het alledaagse zaken betreft, etc. Het hebben van delinquente vrienden wordt bij jongeren dan ook als een van de meest betrouwbare voorspellers van toekomstig delinquent gedrag beschouwd. ${ }^{5}$

Dat brengt ons meteen bij de laatste factor die de kwestie van het zelfstandig oordeelsvermogen aanzienlijk relativeert: de ongunstige omgeving. Van oudsher is bekend dat juist onder jongeren die (herhaaldelijk) ernstige delicten plegen vaak achterstanden in cognitieve en emotionele ontwikkeling worden aangetroffen, die op hun beurt meestal verbonden zijn met falen op school en problemen thuis. Juist voor dergelijke probleemgevallen is de 'eigen groep' van lotgenoten van levensbelang. Het is in dat licht dat ze zichzelf vaak identiteit en recht van bestaan toekennen; en datzelfde licht drukt zwaar op hun vermogen tot zelfstandige oordelen en handelen.

Kortom, in het algemeen kunnen we zeggen dat het zelfstandig oordeelsvermogen rond het zestiende jaar in principe volledig is ontwikkeld, maar ook dat de impulsbeheersing nog verre van voltooid is. Daarnaast moeten we 
vaststellen dat we juist bij de groep die zich op jonge leeftijd schuldig maakt aan ernstige 'volwassen' feiten, veelal te maken hebben met een gebrekkig zelfstandig oordeelsvermogen en een gebrekkig besef van wat men met een dergelijk feit teweeg zou kunnen brengen.

Als we naar de processuele kant kijken, dan blijkt allereerst dat kinderen onder de veertien over het algemeen eenvoudigweg niet echt kunnen doorzien hoe een strafproces werkt en dat ze hun positie daarin niet goed kunnen inschatten. Ze kunnen nog niet op een volwassen wijze redeneren over hun zaak en vooral hun positie daarin noch tot een afgewogen oordeel daarover komen, maar ze kunnen evenmin overzien wat er in een strafproces van hen wordt verwacht. Ze missen met name inzicht in de effecten van hun optreden op degenen die hen moeten beoordelen. ${ }^{6}$ Pas vanaf een jaar of veertien à vijftien zijn zij in principe in staat tot relevante inzichten met betrekking tot de strafrechtelijke procedure die lijken op die van de meeste volwassenen. Vele jongeren ontwikkelen zich echter aanmerkelijk langzamer. Velen verwerven op dit punt pas tegen hun twintigste 'volwassen' vermogens en dat geldt bij uitstek voor de adolescenten die voor de rechter moeten verschijnen.

Deze beperkingen in cognitieve en psychosociale vermogens en vaardigheden krijgen een bijzondere betekenis in het licht van hun optreden in de rechtszaal. In de wereld van de rechtbank kunnen we adolescenten volledig 'kwijtraken', doordat ze die als een andere wereld ervaren met een andere taal en een referentiekader waar zij eigenlijk geen deel van uitmaken. Ze kunnen zich daar bij wijze van primitieve 'overlevingsstrategie' min of meer voor afsluiten. Dit zijn reacties die we met name zien bij adolescenten met een andere etnische achtergrond. Dat betekent dat de kinderrechter ook bij vijftien-, zestien- en zeventienjarigen veelal jongeren tegenover zich heeft die geen idee hebben hoe ze op anderen overkomen, zeker niet op volwassenen. Laat staan dat ze een realistisch inzicht hebben in wat hun optreden teweeg zou kunnen brengen bij het publiek. Dit punt is bijvoorbeeld relevant als we de op zich begrijpelijke publieke verontwaardiging zien met betrekking tot het optreden in de rechtszaal van Murat D. Daar toonde hij zich boos en trots en liet niets zien van empathie of spijt. ${ }^{7}$

6 Scott, Repucci \& Woolard 1995, Steinberg \& Cauffman 1996, Woolard, Reppucci \& Redding 1996.

$7 \quad$ NRC 15 en 29 april 2004 en Algemeen Dagblad 16 april 2004. 
Geconcludeerd kan worden dat juist minderjarigen die ernstige delicten plegen over het algemeen niet als volwassenen kunnen worden beschouwd. Zij vertonen ontwikkelingsachterstanden, zijn niet tot een zelfstandig oordeel in staat geweest vóór en op het moment dat ze het delict pleegden en zijn nauwelijks in staat als volwaardige partij in het strafproces te participeren.

\section{Rechterlijke motiveringen voor de overdracht}

Ik heb tien rechterlijke uitspraken, waaronder die van Murat D., bestudeerd met betrekking tot berechting van minderjarige daders volgens het meerderjarigenstrafrecht. De feiten vonden plaats tussen 1999 en 2004 en de zaken werden door de rechtbanken in eerste aanleg behandeld in de jaren 2000 tot en met 2004. Het betrof de meervoudige strafkamers van de rechtbanken van Den Bosch (3x), Den Haag (2x), Zutphen, Zwolle, Maastricht, Arnhem en Haarlem.

Zeven van deze zaken hadden betrekking op ernstige zaken als moord, poging tot moord en doodslag. Hiervan ging het in drie gevallen om een veroordeling tot uitsluitend gevangenisstraf, variërend van 7 tot 5 jaar. In de andere vier zaken werd gevangenisstraf in combinatie met TBS opgelegd, variërend van 9 maanden gevangenis met TBS tot 8 jaar gevangenis met TBS. Het eerste was het geval bij een duidelijk psychotische gestoorde jongeman die van doodslag werd beschuldigd. Het laatste was het geval bij een meisje van 17, dat van moord op haar ex-partner werd beschuldigd. De deskundigen signaleerden bij haar een sterk gestoorde persoonlijkheidsstructuur en een psychopathische karakterstructuur evenals een zeer sterk beperkte gewetensfunctie. 8 jaar met TBS werd eveneens opgelegd aan de moordenaar van Maja Bradaric, die in november 2003 werd vermoord en verbrand in Bemmel bij Nijmegen.

Dit zijn dus allevier zaken waarin het veiligheidsargument de doorslag gaf: het ging om een zeer ernstig delict; de rechter concludeerde op grond van deskundigenrapportage dat gezien de persoonlijkheid van de dader rekening moest worden gehouden met groot risico van herhaling; uit diezelfde deskundigenrapportage bleek dat dat risico, ondanks behandeling, nog zeer lang zou kunnen blijven bestaan. Kortom, deze dader moest met zekerheid voldoende tijd opgesloten en vooral behandeld kunnen worden.

De drie zaken waarin het ging om een veroordeling tot uitsluitend langdurige gevangenisstraf speelden allemaal in 2001. Twee daarvan deden zich voor in 
Veghel. De eerste zaak betrof de zogenaamde 'Veghelse eerwraak': de oudste zoon van een Turks gezin werd door zijn vader zwaar onder druk gezet om de schaking van zijn zusje te wreken. De jongen, die een blanco strafblad had en verder niet bekend stond vanwege problemen, kreeg van zijn vader een geladen pistool en schoot daarmee op zijn school, een ROC waar de schaker van zijn zusje zich vertoonde, wild om zich heen, gelukkig zonder iemand te doden. De rechtbank van Den Bosch was van oordeel dat de ernst van de feiten berechting volgens het volwassenenstrafrecht rechtvaardigde. Op grond daarvan werd hij wegens poging tot moord en poging tot doodslag veroordeeld tot 5 jaar gevangenisstraf.

Opvallend is hier dat de rechtbank de typische gezinssetting buiten beschouwing liet of daar althans tamelijk lakoniek over sprak. De rechtbank stelde 'Van verdachte kon en mocht meer weerstand worden verwacht tegen de op hem liggende druk. (...) Van hem was te verlangen dat hij zonodig het vaderlijk gezag zou trotseren.' De wijze waarop de rechtbank omging met de beschikbare kennis over de verhoudingen in het traditionele Turkse gezin en ook het feit dat de rechtbank de conclusies van de twee deskundigenrapporten naast zich neerlegde, roept nogal wat vragen op. Maar met name de motivering om in deze zwaar cultureel beladen zaak het volwassenenstrafrecht toe te passen, uitsluitend vanwege de ernst van de feiten, mag als een regelrechte achteruitgang worden beschouwd vergeleken bij de gecombineerde redenering die voorheen gebruikelijk was. ${ }^{8}$ Daarbij moest de overdracht immers behalve door de ernst van de feiten ook door de persoonlijkheid van de verdachte worden gerechtvaardigd.

De tweede zaak betrof een afschuwelijke, geheel koelbloedig voorbereide, herhaalde moordaanslag. De rechtbank in Den Bosch oordeelde in tegenstelling tot het deskundigenadvies, dat hier op een 17-jarige mededader het meerderjarigenstrafrecht diende te worden toegepast. De grond daarvoor zag zij in de ernst van de feiten en de omstandigheden waaronder die waren begaan. Ook hier bleef het aspect van de persoonlijkheid dus buiten beschouwing. De rechtbank legde vervolgens een gevangenisstraf van 7 jaar op.

In de derde zaak ging het om betrokkenheid bij moord door een 17-jarige jongen, die kort daarvoor uit Curaçao was gearriveerd, aan geld kwam via de 
handel in drugs en een voorliefde had voor pistolen. Het deskundigenrapport karakteriseerde de verdachte onder meer als 'verwend en egozwak' en 'erg omgevingsafhankelijk en daardoor erg beïnvloedbaar'. De rechtbank legde de adviezen tot plaatsing in jeugddetentie naast zich neer en besloot tot toepassing van het meerderjarigenstrafrecht, net als in het vorige geval, op grond van de feiten en de omstandigheden. Zij veroordeelde hem tot 5 jaar gevangenisstraf. We zien dus dat in alledrie de gevallen de ernst van de feiten (en eventueel de omstandigheden) de motivering leveren om tot overdracht naar het volwassenenstrafrecht te besluiten. Met die enkelvoudige motivering, waarbij dus de persoonlijkheid van de jongere, en daarmee het feit dat het om een jongere gaat, buiten beschouwing wordt gelaten, distantieert de rechtbank zich in feite principiëel van het jeugdstrafrecht. Daarmee riskeert de rechtbank bovendien dat deze jongeren spoedig tot geharde criminelen zullen kunnen uitgroeien.

Tot slot de drie zaken waarbij de ernst relatief gering was en waarbij dientengevolge relatief lage straffen werden opgelegd. De eerste zaak betrof een 17-jarige die had meegedaan aan een serie gewapende overvallen op winkels in het najaar van 2001 en januari 2002. De jongen was niet eerder veroordeeld. De rechtbank van Den Bosch meende dat het meerderjarigenstrafrecht moest worden toegepast gezien de ernst van de feiten en de persoonlijkheid van de verdachte. Zij legde een gevangisstraf op van 30 maanden, waarvan 10 voorwaardelijk. Hiermee bleef men dus ruimschoots binnen het maximum dat in het kader van jeugddetentie mogelijk was geweest.

De tweede zaak betrof een 17-jarige drugskoerier. De rechtbank van Haarlem oordeelde dat berechting volgens het volwassenenstrafrecht geboden was vanwege de ernst van de feiten, de omstandigheden en de persoonlijkheid van de verdachte. Voorzover uit het verslag van de rechtbank valt op te maken, was er geen deskundigenrapport. Desalniettemin werd de jongen door de rechtbank gekarakteriseerd als een impulsieve en naïeve jongeman die vooraf niet nadenkt over de gevolgen van zijn daad en sterk beïnvloedbaar is door anderen.' De jongen wilde er na de eerste smokkelreis niet mee verder, maar ging onder ernstige bedreiging nog een tweede keer om vervolgens een derde drugstransport te weigeren. Dat werd door de rechtbank opgevat als 'een volwassen benadering', d.w.z. in zijn nadeel. De rechtbank zag ondanks de gesignaleerde pedagogische tekorten geen reden tot specifieke begeleiding: "Verdachte zal op eigen initiatief 
moeten leren met geld om te gaan. Met steun van zijn ouders zou verdachte daartoe in staat moeten kunnen worden geacht." Zij veroordeelde hem tot 36 maanden, waarvan 9 voorwaardelijk. Feitelijk betreft dit dus opnieuw een sanctie die binnen het maximum blijft dat in het kader van jeugddetentie had kunnen worden opgelegd.

De laatste zaak speelde in najaar 2004 en betrof een minderjarige die binnen enkele maanden 15 maal in huizen had ingebroken en ook had meegedaan aan het in omloop brengen van vals geld. Deze jongen had eerder een voorwaardelijke jeugddetentie gekregen van 8 maanden en in dat kader deelgenomen aan een ITB-traject. Maar hij was binnen zeer korte tijd opnieuw en in hoog tempo op inbrekerspad gegaan. De rechtbank Zwolle stelde "dat deze handelswijze van verdachte, indien hij niet tot andere inzichten komt, dan ook het ergste doet vrezen voor de toekomst." Dit maakte in haar ogen verplichte begeleiding in het kader van de reclassering noodzakelijk. Ook hier was, voorzover uit het verslag van de rechtbank valt op te maken, geen deskundigenrapport en dus geen persoonlijkheidsonderzoek uitgevoerd. Toch concludeerde de rechtbank dat de ernst van de feiten, de omstandigheden én de persoon van de verdachte grond gaven om het meerderjarigenstrafrecht toe te passen. Dat werd als volgt beargumenteerd: "dat de feiten getuigen van een weloverwogen keuze en van het doelbewust incalculeren van de daaraan verbonden risico's. Verdachte heeft de feiten op een stelselmatige wijze gepleegd, waarbij hij geen enkel oog heeft gehad voor de gevolgen van zijn handelen voor de slachtoffers en uitsluitend gericht is geweest op het verkrijgen van geldelijke middelen. (...) De rechtbank vindt in dit geval een langdurige grotendeels onvoorwaardelijke vrijheidsstraf noodzakelijk omdat aard en ernst van het bewezen en strafbaar verklaarde, door een lichtere strafrechtelijke afdoening van de zaak miskend zou worden." De jongeman werd veroordeeld tot 1,5 jaar gevangenisstraf, waarvan een half jaar voorwaardelijk, en tot het betalen van een schadevergoeding van ca $€ 2000$.

Opnieuw werd dus een straf opgelegd die ruimschoots binnen het jeugdstrafrecht opgelegd had kunnen worden. Kennelijk nam de rechtbank met deze beslissing, net zoals dat gebeurde in de andere gevallen waarin alleen een gevangenisstraf werd opgelegd, het risico van snelle verharding en van verhoogde kans op recidive voor lief. Dit is des te opvallender gegeven de zorgen die de rechtbank zelf uitte over de toekomst van de verdachte. Verder moeten we constateren dat de feiten zeker niet zéér ernstig zijn. Er was bijvoorbeeld bij geen van de inbraken sprake van geweld, noch 
van bedreiging, noch van gebruik of aanwezigheid van wapens. Ook de omstandigheden lijken niet direct de beslissing tot overdracht naar het volwassenenstrafrecht te rechtvaardigen. En tenslotte is ook het oordeel over de persoon allerminst overtuigend: het feit dat de jongen winst en verlies calculeert zegt weinig over zijn mogelijke volwassenheid.

Juist vanuit het oogpunt van de door de rechtbank geconstateerde noodzaak tot correctie lijkt dit vonnis onbevredigend. Net als bij het voorlaatste vonnis oordeelt de rechtbank dat de jongere het zelf maar moet rooien, dat hij zelf voor verbetering moet zorgen, waar dat nu juist het probleem lijkt. Over de laatste drie zaken, die alledrie qua strafmaat binnen het jeugdstrafrecht hadden kunnen worden afgedaan, kan men zeggen dat de rechtbank daarmee een risico neemt van een slechtere uitkomst ten behoeve van een vergelijkbaar zware sanctie. Het is de vraag of dit maatschappelijk wenselijk is. Toch zit hier niet het echte dilemma, juist omdat gesteld kan worden dat deze zaken met enige goede wil ook binnen het kader van het jeugdstrafrecht hadden kunnen worden afgedaan. Het echte dilemma zit hem naar mijn mening in de gevallen die ik hiervoor besprak: de gevallen waarin zeer ernstige misdrijven waren gepleegd en waar gevaar voor herhaling allerminst denkbeeldig was en waarin vervolgens toch alleen langdurige gevangenisstraf werd opgelegd, omdat er niet sprake leek van een ernstige geestelijke stoornis.

\section{Argumenten tegen en voor}

Ik heb hierboven inzichten uit de ontwikkelingspsychologie en het hersenonderzoek op een rijtje gezet om vervolgens te concluderen dat we adolescenten altijd als onvolwassenen zouden moeten beschouwen. Ik voeg daar een tweede argument tegen een flexibele bovengrens aan toe, een principieel juridisch argument, dat berust op de vergelijking met het civiele recht. Zoals jongeren met betrekking tot hun deelname aan het autoverkeer voor hun achttiende nog geen volledige verantwoordelijkheid wordt gegeven, geldt dat ook voor hun strafrechtelijke verantwoordelijkheid. Ook wat het rijbewijs en het deelnemen aan het verkeer betreft maken we geen uitzondering als in een enkel geval in principe aannemelijk te maken zou zijn dat een jongere wellicht al eerder 'als een volwassene' zou kunnen deelnemen aan het verkeer; we vragen ons dat niet eens af. Terecht beschouwt Franklin Zimring een hoge mate van conformiteit tussen de civiele en de strafrechtelijke status van adolescenten als een criterium voor 
de kwaliteit van een strafrechtelijke cultuur. ${ }^{9}$ Deze twee argumenten om een vaste bovengrens te hanteren in het jeugdstrafrecht sluiten bovendien aan op de tendens in de relevante internationale verdragen. ${ }^{10}$ Wat betreft de formele kant staat art. 495b Sv, dat onder meer inbreuken op het principe van gesloten deuren toestaat, op gespannen voet met art. 40 lid 2 onder vii van het IVRK, dat ieder kind garantie biedt dat zijn of haar privé-leven volledig wordt gerespecteerd tijdens alle stadia van het proces.

Tenslotte is er nog een argument van een heel andere orde tegen overdracht van minderjarigen naar het volwassenenstrafrecht. Dat is een argument ontleend aan de criminologie: uit Amerikaans onderzoek blijkt dat dit althans in de VS de kans op recidive vergroot in plaats van verkleint. Veel meer van de jongeren die als volwassen misdadigers zijn behandeld dan van degenen die volgens het jeugdstrafrecht zijn berecht en behandeld plegen opnieuw misdrijven en ze plegen bovendien opvallend veel zwaardere misdrijven. ${ }^{11}$ Toch betekent dit alles naar mijn mening niet dat de jeugdrechter absoluut en in alle opzichten binnen de grenzen van het jeugdstrafrecht dient te blijven. Wat de formele kant - de positie van de minderjarige in het proces - betreft, denk ik dat er geen tegenargument gevonden kan worden. Maar wat de materiële kant betreft denk ik dat er op zijn minst één goed argument is om daarvan af te wijken. Die reden heeft geen betrekking op de vraag naar de ontwikkeling en de mogelijke volwassenheid van de dader, maar op een heel andere vraag, namelijk betreffende de maatschappelijke veiligheid.

Recidivegevaar geldt onafhankelijk van de ontwikkelingsfase van de verdachte. Indien het om een zeer ernstig delict gaat, en indien de rechter op grond van deskundigenrapportage van mening is dat gezien de persoonlijkheid van de dader rekening moet worden gehouden met groot risico van herhaling, en indien uit diezelfde deskundigenrapportage naar voren komt dat dat risico, ondanks behandeling, nog zeer lang zal blijven bestaan, dan moet dat vanuit veiligheidsoverwegingen kunnen leiden tot overschrijden van de beperkingen die gelden voor de jeugdsancties. Daarvoor geldt immers een maximum van twee jaar detentie en hooguit zes jaar behandeling. Aangezien de sanctiemaat in dergelijke uitzonderlijke gevallen vanuit het oogpunt van maatschappelijke veiligheid aanzienlijk ruimer dient te kunnen worden dan waarin het jeugdstrafrecht voorziet, is de

9 Zimring in Grisso \& Schwartz 2000, 285.

10 Mijnarends 1999.

11 Lanza-Kaduce et al 2002. 
enige weg, die op dit moment voor de kinderrechter begaanbaar is, de overdracht in materieel opzicht naar het volwassenenstrafrecht. Dat zou niet alleen dienen te gebeuren op basis van een typisch jeugdstrafproces, met alle bescherming voor de persoon van de verdachte. Er zouden ook garanties moeten worden ingebouwd om te voorkomen dat de uitkomsten van dergelijke sancties uiteindelijk contraproductief zijn. Dat zal onder meer betekenen dat in dergelijke gevallen uitsluitend zware straf tekort zal schieten. Langdurige TBS, langer dan het maximum in het kader van het jeugdstrafrecht, is daarentegen in principe goed voorstelbaar en verdedigbaar.

Dit is ook de redenering die het gerechtshof bij de zaak in hoger beroep tegen Murat D. heeft gevolgd. Het hof volgt de deskundigenrapportages, waarin zonder uitzondering voor berechting volgens het jeugdstrafrecht en opname in een jeugdinrichting werd gepleit, in zoverre dat het het risico van verharding erkent als Murat in een volwassen omgeving zou worden gedetineerd. Het hof adviseert daarom ten eerste om de TBS-maatregel niet later dan na $1 / 3$ van de opgelegde 5 jaar gevangenisstraf te doen ingaan. Ten tweede adviseert het hof dringend de TBS-maatregel ten uitvoer te leggen in Hoeve Boschoord te Vledder of 'een andere TBS inrichting die de capaciteiten heeft om jongeren in ontwikkeling te behandelen.'

Het hof voegt daaraan toe: "Het zou overigens de voorkeur van het hof hebben indien ook de terbeschikkingstelling - althans het eerste deel daarvan - in een daarvoor geëigende jeugdinrichting ten uitvoer zou kunnen worden gelegd. Dit lijkt met de bestaande regelgeving echter niet mogelijk."

Hier signaleert het hof inderdaad een punt dat in ons strafstelsel onbevredigend is geregeld. Er ontbreekt voor dergelijke ernstige uitzonderingssituaties een vloeiende, logische relatie tussen ons jeugdstrafrecht en het volwassenenstrafrecht. $\mathrm{Er}$ is behoefte aan een speciaal detentie/ behandelingssysteem voor 18-24 jarigen, met name voor de categorie waartoe Murat D. behoort: een gevaarlijke, ernstig in zijn ontwikkeling achtergebleven jongere die een zeer ernstig misdrijf heeft gepleegd en bij wie de kans op herhaling binnen een groot aantal jaren niet uitgesloten moet worden geacht, maar bij wie de kans op aanmerkelijke afname van recidivegevaar juist afhankelijk is van een op zijn problematiek toegeruste inrichting. 


\section{Literatuur}

- Doreleijers, Th. \& Jansen, L. (2004) De biologische ontwikkeling, In J. de Wit, W. Slot \& M. van Aken (Red.) Psychologie van de Adolescentie, Baarn: HB Uitgevers.

- Koops, W. \& W. Slot (red.) (1998) Van lastig tot misdadig. Een ontwikkelingsbenadering van lastige en misdadige kinderen en adolescenten: diagnostiek, behandeling en beleid, Houten/ Digem: Bohn Stafleu Van Loghum.

- Lanza-Kaduce, L., Frazier, C.E., Lane, J. \& Bischop, D.M. (2002) Juvenile transfer to criminal court study: final report, Florida Department of Juvenile Justice.

- Loeber, R., N.W. Slot \& J.A. Sergeant (red.) (2001) Ernstige en geweldadige jeugddelinquentie. Omvang, oorzaken en interventies, Houten: Bohn Stafleu Van Loghum.

- McCord, J., C. Spatz Widom \& N. Crowell (eds.) (2001) Juvenile crime, juvenile justice. Washington: National Academy Press.

- Mijnarends, E.M. (1999) Richtlijnen voor een verdragsconforme jeugdstrafrechtspleging, 'gelijkwaardig maar minderjarig', Proefschrift Universiteit Leiden.

- Scott, E., Reppucci, N. \& Woolard, J. (1995) Evaluating Adolescent Decisionmaking in Legal Contexts, Law and Human Behavior 19, 221244.

- Steinberg, L. \& Cauffman, E. (1996) Maturity of Judgment in Adolescence: Psychosocial Factors in Adolescent Decision-making, Law and Human Behavior 20, 249-272.

- Zimring, F.E. (2000) Penal Proportionality for the Young Offender: Notes on Immaturity, Capacity, and Diminished Responsibility, in: T. Grisso \& R.G. Schwartz (Eds) Youth on Trial. A Developmental Perspective on Juvenile Justice, Chicago/ London: University of Chicago Press, 271-289. 